\title{
A ATUAÇÃO DO PODER JUDICIÁRIO NA CONCRETIZAÇÃO DE DIREITOS FUNDAMENTAIS SOCIAIS NO BRASIL
}

\author{
Heloisa Sami Daou ${ }^{1}$ \\ José Claudio Monteiro de Brito Filho
}

\section{RESUMO}

Artigo que analisa a judicialização de direitos fundamentais sociais no Brasil à luz da Constituição Federal de 1988. Inicialmente, faz-se um estudo sobre o tratamento dado pela Constituição aos direitos fundamentais sociais. Depois, analisa-se o fenômeno da judicialização em conjunto com o conceito de políticas públicas, pois diante da ineficácia prática ou omissão dos Poderes Legislativo e Executivo é crescente o número de demandas judiciais para garantia de direitos sociais. Por fim, o estudo volta-se para compreensão do papel dos direitos fundamentais e do Poder Judiciário em uma Democracia Constitucional.

Palavras-Chave: Direitos Fundamentais Sociais; Política Pública; Judicialização; Poder Judiciário; Democracia Constitucional.

\section{THE ACTING OF THE JUDICIARY POWER IN THE CONCRETIZATION OF SOCIAL FUNDAMENTAL RIGHTS IN BRAZIL}

\begin{abstract}
An article that analyzes the judicialization of fundamental social rights in Brazil in the light of the Federal Constitution of 1988. Initially, a study is made on the treatment given by the Constitution to fundamental social rights. Then, the phenomenon of the judicialization is analyzed together with the concept of public policy, because in face of the practical inefficiency or omission of the Legislative and Executive Powers is increasing the number of lawsuits to guarantee social rights. Finally, the study turns to an understanding of the role of fundamental rights and the Judiciary power in a Constitutional Democracy.
\end{abstract}

Keywords: Social Fundamental Rights; Public Policy; Judicialization; Judiciary Power; Constitutional Democracy.

\footnotetext{
${ }^{1}$ Mestranda do programa de Pós-Graduação stricto sensu do Centro Universitário do Estado do Pará - CESUPA. E-mail: helo_daou@yahoo.com.br.

${ }^{2}$ Doutor em Direito das Relações Sociais pela PUC/SP. Professor dos Programas de Pós-Graduação em Direito da UFPA e do CESUPA. E-mail: jclaudiobritofilho@gmail.com.
} 


\section{INTRODUÇÃO}

A atuação do Poder Judiciário na concretização de direitos fundamentais sociais é assunto de grande relevância e continua suscitando inúmeros debates na doutrina e na jurisprudência.

Nesse sentido, a Constituição da República Federativa do Brasil de 1988 (CRFB/88) é paradigmática, pois reconheceu toda força e fundamentalidade dos direitos sociais. Portanto, a Carta Magna simboliza um marco jurídico de democracia e institucionalização dos direitos fundamentais no País, uma vez que o valor da dignidade da pessoa humana, como fundamento do Estado Democrático de Direito, sobre o qual se funda o Brasil, insculpido no art. $1^{\circ}$, III da CRFB/88 impõe-se como núcleo básico de toda hermenêutica do sistema jurídico, como critério de valoração e baliza de atuação estatal.

De acordo com o modelo de Estado Social de Direito, adotado a partir da CRFB/88, o Estado sai da posição de mero expectador e passa a intervir no campo econômico e social, tornando-se sujeito ativo do desenvolvimento e da justiça social, devendo prestar todas as necessidades do ser humano, sem discriminação e em sua melhor forma de eficácia. Ou seja, toda ação do Estado deve estar direcionada para concretização dos seus fins característicos, sendo, esta, inclusive, a exigência dos fundamentos da República, especialmente da dignidade da pessoa humana.

A atuação do Estado para garantia de direitos fundamentais se dá por meio das políticas públicas, originalmente elaboradas e executadas pelos Poderes Legislativo e Executivo. Por essa razão, devem-se compreender as políticas públicas como uma categoria normativa, com a função jurídica de realizar a intermediação dos anseios da sociedade diante do Estado e dos governos, buscando esquematizar os interesses de todos os seguimentos sociais e os interesses dos indivíduos para uma concreta realização de direitos.

Por outro lado, e não obstante o mandamento constitucional, na prática, o que se observa é que a efetivação de direitos sociais ainda encontra óbice, especialmente pela ineficácia e/ou omissão do Estado na realização de políticas públicas.

Nesse diapasão, resta evidente que os Poderes Executivo e Legislativo possuem suas funções típicas definidas na Constituição e não deve o Judiciário usurpar para si atuação que não lhe pertence. Por outro lado, quando chamado a intervir e diante da lesão de direitos fundamentais, que se dá na maioria das vezes pela omissão ou inércia dos demais Poderes, não 
pode o Judiciário se esquivar, mesmo que, para tanto, acabe atuando, de alguma forma, em uma esfera política. Dessa forma, o choque entre a vontade do legislador, a atuação do administrador e a determinação do juiz na tentativa de garantir o texto constitucional é quase inevitável.

A missão de fazer valer o mandamento constitucional sempre que provocado, especialmente aquele relacionado aos direitos fundamentais sociais, faz com que o Poder Judiciário assuma uma nova feição, como exigência do próprio Estado Constitucional Social e Democrático de Direito. E, mais ainda, as decisões devem tutelar efetivamente os direitos envolvidos, sejam eles de uma classe representada de indivíduos ou de apenas uma pessoa singularmente considerada, isso como exigência própria de justiça social e máxima do princípio da dignidade da pessoa humana.

Importante destacar que, se por um lado a atuação do poder judiciário é essencial para que a democracia se materialize e a constituição alcance toda sua eficácia pratica, por outro, essa atuação do Judiciário deve ser compatível com a democracia, justamente para que não ocorra uma intromissão nas atribuições dos demais poderes.

O presente artigo tem como objetivo analisar a judicialização de direitos fundamentais sociais no Brasil à luz da CRFB/88. Para tanto, este ensaio está dividido em três partes.

Inicialmente, far-se-á um estudo sobre o tratamento dado pela Constituição aos direitos fundamentais sociais. Depois, analisar-se-á, o fenômeno da judicialização em conjunto com o conceito de políticas públicas, pois diante da ineficácia prática ou omissão dos Poderes Legislativo e Executivo tem sido crescente a demanda por atuação do Judiciário na garantia de direitos fundamentais sociais. Por fim, o estudo volta-se para compreensão do papel dos direitos fundamentais e do Poder Judiciário em uma Democracia Constitucional.

O presente texto é uma obra de hermenêutica Constitucional. Para atingir os objetivos elencados a metodologia empregada foi a da revisão bibliográfica de livros e artigos científicos sobre o tema. Partir-se-á, neste momento, à compreensão do tratamento dado pelo constituinte de 1988 aos direitos fundamentais sociais: 


\section{DIREITOS SOCIAIS FUNDAMENTAIS NA CONSTITUIÇÃO DA REPÚBLICA FEDERATIVA DO BRASIL DE 1988}

A CRFB/88 legitima o Estado Social e Democrático de Direito (art. $1^{\circ}$ ) e traz um catálogo de direitos sociais (art. $6^{\circ}$ ), todos inseridos no rol dos direitos fundamentais (art. $5^{\circ}$ a 17). A formação desse catálogo de direitos fundamentais é, portanto, fruto da luta de grupos sociais que almejaram, em cada momento da história da sociedade, o reconhecimento e a garantia de suas necessidades fundamentais. Assim, o Brasil, além de ser um Estado Democrático no que diz respeito ao Poder Político, é um Estado Social no que diz respeito à atuação do Estado.

Para atingir seus objetivos fundamentais, "o Estado tem que se organizar no facere e prestare, incidindo sobre a realidade social. É ai que o Estado Social de direito transforma-se em Estado Democrático de direito" (GRINOVER, p. 11).

Somado a isso, nas primeiras linhas do texto constitucional fica evidente que, desde 1988, a dignidade da pessoa humana é o valor fundamental da ordem jurídica brasileira, princípio-matriz de toda atuação estatal, elencada como fundamento do Estado brasileiro ${ }^{3}$, razão pela qual se pode afirmar: "é o Estado que existe em função da pessoa humana, e não o contrário, já que o ser humano constitui a finalidade precípua, e não o meio da atividade estatal" (SARLET, 2012, p. 80), ou ainda "O Estado está a serviço da pessoa humana "(ALCALÁ, 2009, p. 146) ${ }^{4}$.

Assim, o constituinte eleva o homem à condição de elemento central e impõe ao Estado o dever de garantir a mais variada gama de direitos e liberdades, tudo com vistas ao bem-estar do ser humano. Dias (2007, p. 116) afirma que "A dignidade da pessoa humana impõe-se como uma base estrutural sobre a qual os sistemas jurídicos modernos são construídos”.

Nesse contexto, o fundamento da dignidade da pessoa humana concede unidade de sentido à realização dos direitos sociais fundamentais e impõe ao Estado o dever de sua garantia em toda e qualquer atuação. Isso porque, na garantia de direitos fundamentais vê-se garantida a dignidade, atributo de todos os seres humanos.

\footnotetext{
${ }^{3}$ Art. $1^{\circ}$ da CRFB/88 - A República Federativa do Brasil, formada pela união indissolúvel dos Estados e Municípios e do Distrito Federal, constitui-se em Estado Democrático de Direito e tem como fundamentos: (...); II - a cidadania; III - a dignidade da pessoa humana; (...).

${ }^{4}$ No original: El Estado está al servicio de la persona humana (ALCALÁ, 2009, p. 146).
}

Rev. de Direitos Fundamentais nas Relações do Trabalho, Sociais e Empresariais | e-ISSN: 2525-9903 | Maranhão | v. 3 | n. 2 | p. 44 - 65 | Jul/Dez. 2017. 
Os direitos sociais estão dispostos na CRFB/88 no Título II, destinado aos direitos e garantias fundamentais, Capítulo II, que versa sobre a ordem social, que tem como objetivo o bem-estar e a justiça social. $\mathrm{O}$ art. $6^{\circ}$ da CRFB/88 estabelece como direitos sociais fundamentais a educação, a saúde, a alimentação, o trabalho, a moradia, o lazer, a segurança, a previdência social, a proteção à maternidade e à infância e a assistência aos desemparados.

Ao reconhecer a estes direitos uma dimensão fundamental, o Estado obrigou-se a prestações positivas que os garantam a todos na integralidade. Ou seja, o constituinte estabelece os direitos fundamentais como baliza para atuação do Estado, basta observar a localização do dispositivo legal, logo no início do texto constitucional, para compreender que o constituinte quis desenvolver toda organização da República Federativa do Brasil a partir desse conjunto essencial básico que deve ser garantido aos indivíduos.

A própria Constituição já elenca a forma de atuação estatal, por meio de políticas públicas para garantia de direitos fundamentais sociais. Concretamente, cabe ao Estado a promoção da dignidade assegurando prestações materiais que possibilitem um maior número de liberdades para que os seres humanos desenvolvam seus projetos racionais de vida. $\mathrm{O}$ resultado é a realização e eficácia do texto constitucional, deixando seu caráter meramente retórico.

Os direitos fundamentais são, portanto, uma garantia de vida melhor que foi concedida pelo constituinte a todos os seres humanos. Eles são posições jurídicas essenciais a todas as pessoas, porque decorrentes, de uma forma ou de outra, da sua dignidade.

Desse modo, os direitos sociais fundamentais possuem uma tríplice característica: o Estado está obrigado a proporcioná-los aos indivíduos, ou a todos eles; eles são (frisa-se, todos eles), um mínimo existencial, sem eles não há condições de vida digna e, ainda, eles são direitos essenciais para todas as pessoas.

Logo, não há diferença substancial entre os direitos civis e políticos e os direitos econômicos, pois todos exigem uma conduta do Estado, comissiva ou omissiva, em menor ou maior grau. Assim, todos os direitos fundamentais são essenciais. E, mais ainda, a garantia de todos e de cada um é necessária para promoção da dignidade da pessoa humana, pois eles fazem parte de um mínimo necessário para a existência em condições de dignidade.

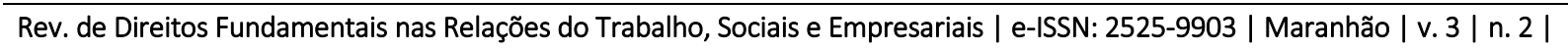
p. 44 - 65 | Jul/Dez. 2017. 
As políticas públicas sociais de responsabilidade, especialmente dos Poderes Legislativo e Executivo, são a via primeira de materialização dos direitos sociais fundamentais e normas constitucionais definidoras de tais direitos e são, ainda, mais do que simples programas de governo, verdadeiras normas jurídicas, dotadas, assim, de imperatividade.

Política pública é um elemento ainda novo na seara jurídica, mas o seu estudo demonstra sua total relevância como instrumento para que o direito deixe de figurar apenas no plano formal para tornar concreto o conteúdo das normas jurídicas aos cidadãos. Essa é uma característica indispensável para o Estado Social, gestado no século XIX, no qual se funda a República Federativa do Brasil, que traz consigo um novo conceito de cidadania aflorado no século XX.

Igualmente a partir do século XIX toma força a corrente econômica vigente até os dias atuais, na afirmação da necessidade de intervenção do Estado na economia, de modo a atenuar as desigualdades econômicas, os contrastes sociais e melhorar o bem estar das pessoas. A teoria do Estado Social se caracteriza por esta atuação estatal na garantia do mínimo existencial às pessoas, garantia de direitos e adoção de políticas públicas com efeitos redistributivos (SMANIO, 2015, p.2).

Assim, as políticas públicas são arranjos complexos, típicos da atividade políticoadministrativa. Referem-se a institutos diversos com incidências em várias áreas do conhecimento e atuação humana, por isso também o direito deve conhecer e descrever, pois elas norteiam toda a atividade do Estado para consecução de direitos das pessoas.

Estes arranjos estão diretamente ligados aos fundamentos da República elencados na Constituição cidadã de 1988, especialmente de dignidade da pessoa humana. Portanto, as políticas públicas são verdadeiras categorias jurídicas normativas, assim como os princípios jurídicos e as regras jurídicas. Por isso, importante destacar o conceito de Dworkin (2010, p. 37) de políticas públicas:

Denomino "política" aquele tipo de padrão que estabelece um objetivo a ser alcançado, em geral uma melhoria em algum aspecto econômico, político ou social da comunidade (ainda que certos objetivos sejam negativos pelo fato de estipularem que algum estado atual deva ser protegido contra mudanças adversas).

Esse conceito traz em si uma importância fundamental, pois, segundo destaca Smanio (2013, p. 5), “(...) ainda nos EUA, coube a Ronald Dworkin, no final da década de 1970, o 
entendimento de que o tema Políticas Públicas também deveria caber na Teoria Geral do Direito".

De mais a mais, não restam dúvidas do interesse jurídico deste conceito, dado o caráter do nosso Estado Social e a imposição da nossa Constituição. A realidade social, atualmente, impõe ao Estado uma grande gama de atividades em prol da garantia da cidadania e efetivação de direitos sociais fundamentais, aqui entendidos como um mínimo necessário para uma vida digna. "O Estado Social legitima-se, antes de tudo, pela realização de políticas, isto é, programas de ação" (GRAU, 2005, p. 26).

Ainda sobre a conceituação de políticas públicas, Bucci (2006, p. 39) assevera que são:

Programas de ação governamental que resulta de um processo ou conjunto de processos juridicamente regulados - processo eleitora, processo de planejamento, processo de governo, processo orçamentário, processo legislativo, processo administrativo, processo judicial - visando coordenar os meios à disposição do Estado e as atividades privadas, para a realização de objetivos socialmente relevantes e politicamente determinados.

Desse modo, as políticas públicas sociais de responsabilidade, especialmente, dos Poderes Legislativo e Executivo, são a via primeira de materialização dos direitos sociais fundamentais e normas constitucionais definidoras de tais direitos e são, ainda, mais do que simples programas de governo, já que verdadeiras normas jurídicas, dotadas, assim, de imperatividade.

Nesse sentido, "não há como não fixarmos um conceito jurídico de políticas públicas, pois estas são também fenômeno jurídico, que pode ser realizado, executado, controlado, enfim efetivado juridicamente" (SMANIO, 2013, p. 10).

E ainda:

O Estado assume a tarefa de proporcionar prestações necessárias e serviços públicos adequados para o pleno desenvolvimento da personalidade humana, por meio da realização de fins materiais. Para cumprir os ideais de Estado Social, a ação dos governantes deve ser racional e planejada, o que ocorre por meio da elaboração e implementação de políticas públicas.

As políticas públicas, definidas como programas de ação governamental voltados à concretização dos direitos fundamentais, (...) (DUARTE, 2013, p. 16-17).

O Estado deve ter atuação decisiva na formulação das políticas públicas voltadas para realização de direitos fundamentais, especialmente os sociais, diminuição de desigualdade na 
aquisição de serviços públicos a partir do planejamento, com a utilização de instrumentos de participação social fomentando o debate sobre os assuntos relevantes para a população. E, após isso, deve atuar na execução dessas medidas com vistas à eficiência e adequação, além de trabalhar sempre com a transparência de modo que os cidadãos possam controlar o alcance dos objetivos e metas almejados.

Quando a atuação do Estado não se dá desta forma ou quando ele não atua quando deveria garantir direitos fundamentais, cresce a judicialização, conforme será exposto na próxima seção.

\section{A JUDICIALIZAÇÃO DE DIREITOS FUNDAMENTAIS SOCIAIS}

Não obstante o mandamento constitucional, na prática, o que se observa é que a efetivação dos direitos fundamentais sociais ainda encontra óbice, tanto em razão de ainda existir resistência de parte da doutrina à plena e incondicional realização desses direitos, a partir da força dos argumentos negativos de fundamentalidade, quanto pela argumentação, - que mais interessa nos limites deste trabalho - de que esses direitos são afetos à decisões políticas, que, portanto, devem obedecer critérios de escolha dos administradores, pois exigem, dentre outras coisas, gerenciamento de recursos financeiros, o que deve ser feito pelos poderes Executivo e Legislativo.

Ocorre que, a ineficácia prática das políticas públicas garantidoras de direitos sociais faz aumentar o número de demandas frente ao Poder Judiciário, que se vê diante da necessidade de intervir, seja para fiscalizar uma política pública ou mesmo para impor ao Estado a concessão de um medicamento, no caso da saúde, por exemplo, ou a garantia de uma vaga na escola, no caso da educação, e muitos outros exemplos que cotidianamente pendem de decisão na mesa dos magistrados.

Desse modo, "Judicialização significa que questões relevantes do ponto de vista político, social ou moral estão sendo decididas, em caráter final, pelo Poder Judiciário" (BARROSO, 2013, p. 228-229). Ou seja, a judicialização transfere para o Poder Judiciário decisão que, originalmente, deveria ser dos Poderes Legislativo e Executivo.

Como é sabido, os Poderes Legislativos e Executivo são instâncias políticas tradicionais, Poderes que se compõem por meio do voto popular, aos quais a Constituição

Rev. de Direitos Fundamentais nas Relações do Trabalho, Sociais e Empresariais | e-ISSN: 2525-9903 | Maranhão | v. 3 | n. 2 | p. 44 - 65 | Jul/Dez. 2017 
relaciona a missão primeira de garantir direitos sociais por meio de políticas públicas, como foi especificado nos tópicos acima.

Por outro lado, a expansão da jurisdição e, assim, da possibilidade de intervenção do judiciário nestas questões reflete uma mudança estrutural de pensar o direito e é fruto de conjunturas diversas, sendo um acontecimento mundial. Exemplos numerosos de judicialização demonstram que entre a política e a justiça há uma linha tênue no mundo contemporâneo, e nem sempre é tão clara essa divisão de criação e interpretação do direito. Os precedentes podem ser encontrados ao redor do mundo, como no Canadá, Estados Unidos, Israel, Turquia, Hungria, Coreia, dentre outros (BARROSO, 2013, p. 229).

Assim, o judiciário se tornou mais forte $\mathrm{e}$ independente, isso como elemento indispensável nas democracias modernas, ao passo que cresceu a desesperança na política majoritária face à crise de representatividade dos parlamentos. No Brasil o fenômeno é crescente e, com destaca Barroso (2013, p. 230):

assumiu proporção ainda maior, em razão da constitucionalização abrangente e analítica - constitucionalizar é, em última análise, retirar um tema do debate político e trazê-lo para o universo das pretensões judicializáveis - e do sistema de controle de constitucionalidade vigente entre nós, em que é amplo o acesso ao Supremo Tribunal Federal por via de ações diretas.

No Brasil, portanto, qualquer questão de relevância política, social ou moral pode ser apreciada pelo Judiciário, ainda mais quando se trata da realização de direitos fundamentais.

Além disso, destaca Oliveira (p. 16):

a concepção dos direitos fundamentais como normas objetivas supremas do ordenamento jurídico reveste-se de capital importância prática, não só teórica, para as tarefas do Estado. Por isso qualquer poder do Estado tem uma obrigação (negativa) de se abster de ingerências no âmbito protegido pelos direitos fundamentais, como também uma obrigação (positiva) de levar a cabo tudo que sirva para a realização dos direitos fundamentais, inclusive quando não diga respeito a uma pretensão subjetiva dos cidadãos.

Nesse sentido, as Constituições contemporâneas desempenham dois importantes papéis, enumerados nos seguintes termos por Barroso (2013, p. 238):

(i) o de condensar os valores políticos nucleares da sociedade, os consensos mínimos quanto a suas instituições e quanto aos direitos fundamentais nela consagrados; e (ii) o de disciplinar o processo político democrático, propiciando o governo da maioria, a participação da minoria e a alternância 
do poder. Pois este é o grande papel de um tribunal constitucional, do Supremo Tribunal Federal, no caso brasileiro: proteger e promover os direitos fundamentais, bem como resguardar as regras do jogo democrático.

Na prática, o Estado deve planejar e executar políticas públicas e serviços públicos que garantam direitos sociais a todas as pessoas, mas deve também garantir a cada pessoa individualmente. Em outras palavras: o Estado deve assegurar esses direitos à coletividade, mas não pode se escusar de nenhum indivíduo, porque ao lado do interesse geral há o interesse pessoal e as pessoas vão manifestar necessidades diferentes. "Cuida-se, portanto, de direito de todos e de cada um, de tal sorte que o desafio é saber harmonizar, sem que ocorra a supressão de uma das dimensões, ambas as perspectivas." (SARLET, 2013, p. 171-172).

A judicialização é maior quanto maior for a omissão dos demais Poderes ou quando estes Poderes, embora atuantes, não estão atendendo o ideal do legislador e assim, sonegando ao cidadão os direitos fundamentais do qual é titular. Nesse sentido, a judicialização pode ser vista como:

A judicialização das políticas públicas acontece, via de regra, na concretização
de direitos fundamentais e não deve ser vista como uma intromissão anômala
de um poder sobre o outro. Não se trata de uma disfunção em face do princípio
da separação dos poderes, mas corrobora a regra do check and balance, pela
qual existe a saudável possibilidade de cada poder estatal interferir no outro,
para controle e alinhamento das respectivas atuações, em busca da melhor
concretização do projeto de país e sociedade que foi desenhado na carta
institucional. (CASTRO; VALLE; ANSCHAU; FERREIRA, 2012, p. 22-23).

Portando, diante de uma lesão aos direitos sociais o judiciário é legítimo para intervir, tanto em demandas coletivas quanto individuais, e o progressivo aumento dessas demandas envolvendo esses direitos fundamentais é um indicativo de falha na prestação de serviços por parte do Estado, o que não pode ser aceito e não se justifica diante das características de imperatividade das normas, como foi visto até aqui.

Por outro lado, ainda há muita resistência em relação à atuação do judiciário no controle das políticas públicas de direitos fundamentais sociais, pois, para muitos autores, pensar numa atuação irrestrita também não se mostra a melhor solução, uma vez que o Judiciário não tem a visão geral das necessidades sociais e dos recursos disponíveis.

Ademais, a atuação do Judiciário é maior, pois a democracia exige garantia de direitos fundamentais sociais e, nesse sentido, há uma certa desesperança nos cidadãos relacionada aos processos democráticos e mesmo na atuação dos seus eleitos. Contudo, mesmo diante disso a 
atuação do Judiciário não está inume de críticas. E, muitas delas seguem como destacado por Leal (2013, p. 443):

Percebe-se o grave problema pelo qual passa o modelo clássico de democracia no mundo inteiro. Nesse contexto de decepção quase generalizada com os mandatários, temos visto crescer o papel da chamada jurisdição constitucional. Fala-se que a ascenção [sic] das cortes constitucionais nos países democráticos está desembocando numa suposta ditadura das togas. $\mathrm{O}$ argumento é que as nações estariam sendo dirigidas por sábios, numa espécie de aristocracia judicial (LEAL, 2013, p. 433).

Estas são questões que precisam ser enfrentadas, pois o judiciário "não pode ser permanentemente canal de reivindicação e, quando isso acontece, é sinal claro de que outros canais estão obstruídos (...)” (SANSON, 2013, p. 125).

Assim, tratar do assunto da judicialização é adentrar em um campo delicado. Ao juiz é feita uma alta exigência. Estará nas mãos dele a interpretação de diversos dispositivos legais e caberá a ele encontrar um sentido decorrente dessa interação de valores, desta mistura de conteúdo, sempre fazendo a melhor ponderação.

Portanto, na próxima seção tratar-se-á do papel dos direitos fundamentais e do Poder Judiciário em uma democracia Constitucional, visando à compreensão sobre como deve ser a forma de atuação do Judiciário na fiscalização de Políticas Públicas.

\subsection{O PAPEL DOS DIREITOS FUNDAMENTAIS E DO PODER JUDICIÁRIO EM UMA DEMOCRACIA CONSTITUCIONAL}

Em que pese tudo que foi dito acerca dos direitos fundamentais sociais e sua essencialidade para a vida digna, há argumentos mais conservadores que, com base no fato de o constituinte ter relacionado a garantia desses direitos às políticas públicas, defendem que o método de concretização de direitos sociais passaria, obrigatoriamente, por instâncias políticas que teriam, assim, a missão de regulamentar os dispositivos constitucionais, para, só assim, poder esses direitos serem reclamados por seus titulares judicialmente, caso fosse necessário.

Segundo esses argumentos, a garantia do grupo de direitos fundamentais sociais depende de prestações positivas do Estado e isso requer o gerenciamento de orçamento e recursos públicos. Portanto, matéria afeta à política. Ademais, acrescenta Barroso (2013, p.

Rev. de Direitos Fundamentais nas Relações do Trabalho, Sociais e Empresariais | e-ISSN: 2525-9903 | Maranhão | v. 3 | n. 2 | p. 44 - 65 | Jul/Dez. 2017. 
239): "Na política, vigoram a soberania popular e o princípio majoritário. O domínio da vontade. No direito, vigora o primado da lei (the rule of law) e do respeito aos direitos fundamentais. O domínio da razão".

Barroso destaca que não há uma separação entre direito e política no campo da criação, isso porque o produto de criação do direito é o processo constituinte ou legislativo que se dá por vontade das maiorias. Contudo, para o autor, no plano da aplicação do direito a sua separação com a política é possível e desejável (BARROSO, 2013, p. 239-240).

Nota-se, nesse tipo de argumentação, que há uma suposta defesa do princípio democrático para limitar a garantia dos direitos sociais somente a atuação dos Poderes Legislativos e Executivo, pois estes representam, em tese, o povo e os Estados.

Assim, para quem pensa dessa forma, permitir que o Judiciário tenha o poder de obrigar o Estado a dar cumprimento à dispositivos constitucionais não é coerente com a democracia, pois o Poder Judiciário tem a característica de não ser composto por representantes eleitos pelo povo e, portanto, não se pode conceder a ele o poder de elaborar e executar políticas públicas. É o que destaca Barroso (2013, p. 235):

Juízes e membros dos tribunais não são agentes públicos eleitos. Sua investidura não tem o batismo da vontade popular. Nada obstante isso, quando invalida atos do Legislativo ou do Executivo ou impõe-lhes deveres de atuação, o judiciário desempenha um papel que é inequivocamente político. Essa possibilidade de as instâncias judiciais sobreporem suas decisões às dos agentes políticos eleitos gera aquilo que em teoria constitucional foi denominado de dificuldade contramajoritária.

Contudo, na prática, o poder político do cidadão é tanto maior quanto maior for o seu poder de influência sobre as instâncias políticas. E, exatamente em razão do fato dos políticos serem eleitos pelo povo que acabam ficando mais expostos às pressões dos cidadãos; porém, nem todos conseguem essa influência, mas apenas aqueles que possuem condições para isso.

Assim, o poder econômico, a educação, a capacidade de ser assistido por bons advogados, dentre outros fatores, são variáveis que desigualam os diversos grupos sociais, no que diz respeito à efetiva participação nas decisões políticas. Assim, "nenhuma democracia proporciona a igualdade genuína de poder político" (DWORKIN, 2005, p.31).

Como é sabido também, em não raros os casos na história da humanidade, pela vontade da maioria, foram cometidas atrocidades contra grupos minoritários, com total desrespeito a dignidade do ser humano. Por isso, mais adequada é a concepção de democracia que conjugue 
a regra da maioria com o resguardo dos direitos fundamentais do indivíduo (BRITO FILHO, 2015, p. 111-266).

Em outras palavras:

[a] democracia exige mais do que apenas aplicação da regra majoritária. É preciso que, juntamente com ela, sejam respeitados os direitos fundamentais de todos os indivíduos, façam eles parte da maioria ou não (BARCELLOS, 2011, p. 266).

Desse modo, para Dworkin, é preciso que haja diferenciação entre questões de política e questões de princípios, pois as questões de política são aquelas relacionadas à promoção do bem-estar geral ou do interesse público: a comunidade adota um programa particular com o qual ela acredita que estará melhorando a vida de todos; enquanto que as questões de princípios estão relacionadas às pessoas individualmente consideradas, o que permite, inclusive, que um programa particular seja rejeitado tão-somente porque geraria um impacto negativo inaceitável sobre os indivíduos específicos, ainda que tal programa, caso implementado, melhorasse sobremaneira a vida da comunidade, quando tida como um todo (DWORKIN, 2005, p. IX).

Assim, para o autor, as questões de princípios são, justamente, os direitos e garantias fundamentais, que, em face da vontade da maioria, exercem a função contramajoritária de "proteger os cidadãos (ou grupos de cidadãos) contra certas decisões que a maioria pode querer tomar, mesmo quando essa maioria age visando o que considera ser o interesse geral ou comum" (DWORKIN, 2010, p. 209).

Para Oliveira (p. 15), o aparecimento da teoria dos princípios de Dworkin e o robustecimento dos direitos fundamentais fizeram com que ocorressem significativas mudanças na lógica jurídica, decisivas para o declínio do normativismo legalista. Isso porque:

os direitos fundamentais exibem acentuada força de irradiação sobre o direito legislado, a acentuar ainda mais o papel do juiz na "descoberta" do direito aplicável ao caso concreto.

Realmente, já não mais se discute na doutrina do direito constitucional o papel dos direitos fundamentais e das normas de princípio - mesmo daquelas consideradas meramente programáticas - consideradas diretivas materiais permanentes, vinculando positivamente todos os órgãos concretizadores, inclusive aqueles encarregados da jurisdição, devendo estes tomá-las em consideração em qualquer dos momentos da atividade concretizadora. 
O Estado brasileiro, como foi dito, não é apenas um Estado Democrático, mas um Estado Democrático e Social de Direito, ou seja, uma democracia constitucional. Assim, a discussão deixa de ser somente a regra da maioria, e passa a ser a igualdade de poder político, uma igualdade real, concreta e efetiva, em que os direitos fundamentais de todos os indivíduos são mantidos a salvo, para que eles possam usufruir, além da liberdade como autonomia, como já tratado anteriormente, também da efetiva liberdade de participação nas decisões políticas da comunidade (SARLET, 2015, p. 61).

Nesse sentido, destaca Grinover (p. 13):

O controle da constitucionalidade das políticas públicas pelo Poder Judiciário, assim, não se faz apenas sob o prisma da infringência frontal à Constituição pelos atos do Poder Público, mas também por intermédio do cotejo desses atos com os fins do Estado.

É dizer que os Poderes Constituídos pelo povo não podem, em suas decisões, desconsiderar direitos fundamentais, ainda que sob o argumento relacionado à vontade da maioria, isso porque a garantia desses direitos está afeta à própria razão de ser do Estado social e democrático de direito.

Assim, quando o Constituinte incluiu um vasto catálogo de Direitos Fundamentais na Constituição, retira-os do debate puramente político e leva-os a esfera do direito. Por isso, afirma Dias (2007, p. 99):

O controle judicial, assim, manifesta-se como uma salvaguarda institucional, a fim de garantir a existência de um modo de vida capaz de respaldar os direitos fundamentais dos cidadãos que integram uma sociedade.

Em outra obra, o mesmo autor acrescenta:

Os direitos fundamentais exercem uma tripla função na dinâmica jurídica de uma sociedade contemporânea que assuma o modelo de Estado democrático de Direito regido pelo Constitucionalismo: a) função fundamentadora do ordenamento jurídico, b) função hermenêutica, c) função de guia para a formulação de políticas públicas. (DIAS, 2013, p.09).

Ademais, a configuração do Estado do bem-estar trouxe significativas transformações sociais, onde os direitos fundamentais, sobretudo os sociais, são considerados os "pilares éticojurídico-políticos da organização do Estado, do Poder e da Sociedade, servindo de parâmetros ou vetores guias para a interpretação dos fenômenos jurídicos-constitucionais." (CUNHA JÚNIOR, 2010, p. 281). 
Desse modo, faz-se necessária uma releitura do dogma da Separação dos Poderes e, com base nele, não se pode mais negar ao Judiciário intervenção nas políticas a cargo dos demais poderes para garantia de direitos fundamentais sociais.

Outrossim, a atuação do Judiciário face a inércia dos demais Poderes não pode ser vista como intervenção anômala, isso porque se o Executivo e Legislativo atuassem a contento na concretização de direitos fundamentais sociais, tal como estabelece a Constituição, não haveria necessidade de intervenção do Poder Judiciário, é o que acrescenta Cunha Júnior (2010, p. 283):

Na verdade, o Judiciário está atuando exatamente pelo fato da não atuação dos outros Poderes. E há uma lógica nisso. Em face de sua atuação substitutiva e supletiva, se não há violação de direitos não há a intervenção do Judiciário. Do contrário, diante da omissão dos outros Poderes, a atuação do Judiciário é exigida pela sociedade para fazer valer o primado da Constituição e do Direito.

A CRFB/88, por sua vez, juntamente com a inovação em relação à fundamentalidade dos direitos sociais, também é profundamente paradigmática em relação à função do Poder Judiciário no âmbito do Estado Social, diante das omissões dos demais poderes face às exigências constitucionais relacionadas à garantia de direitos sociais.

Nesse sentido, Ferraz Júnior (2000, p. 345), considera que houve uma alteração da própria neutralidade do Judiciário em assuntos envolvendo direitos sociais, e, em relação à mudança introduzida pela Constituição afirma:

altera a função do Poder Judiciário, ao qual, perante eles ou perante a sua violação, não cumpre apenas julgar no sentido de estabelecer o certo e o errado com base na lei (responsabilidade condicional do juiz politicamente neutralizado), mas também e sobretudo examinar se o exercício discricionário do poder de legislar conduz à concretização dos resultados objetivos (responsabilidade finalística do juiz que, de certa forma, o repolitiza).

Desse modo, para o autor, o Poder Judiciário também é responsável pelo sucesso das políticas públicas de finalidade, inicialmente, dos demais poderes voltadas às exigências do Estado Social. Desse modo, embora o Constituinte não atribua ao juiz a função de criação dessas políticas, atribui-lhe irrecusável função de impor execução nos moldes do determinado pelo Constituinte.

Rev. de Direitos Fundamentais nas Relações do Trabalho, Sociais e Empresariais | e-ISSN: 2525-9903 | Maranhão | v. 3 | n. 2 | p. $44-65$ | Jul/Dez. 2017 
Logo, na realidade do Estado Social o juiz tem por dever assumir a atividade criadora das soluções requeridas pela sociedade, consistentes na promoção de direitos sociais, do contrário, acaba: "mostrando-se incapaz de garantir a efetividade dos direitos fundamentais, máxime dos direitos sociais, na prática acaba sendo conivente com sua sistemática violação" (CUNHA JÚNIOR, 2010, p. 285).

Assim, é cada vez maior a exigência de controle judicial na implementação de políticas públicas destinadas à plena satisfação de direitos sociais. Logo, na hipótese de o Judiciário não assumir com esta nova responsabilidade de coparticipação no processo de construção da sociedade do bem- estar e, segundo Faria (2002, p. 40):

não renovar sua cultura técnico-profissional, permanecendo atrelado a uma visão-de-mundo liberal clássica, sem compreender que quanto mais programáticas forem as normas dos direitos sociais, maior é o espaço deixado à discricionariedade das decisões judiciais" ele "corre o sério risco de ver a ordem jurídico-positiva fragmentada e despedaçada por uma sociedade dividida, contraditória e explosiva; uma sociedade que, nos segmentos mais desfavorecidos, não tem achado socorro tanto na Constituição quanto na imensa profusão de leis e códigos em vigor.

Pelo que se observa, os direitos fundamentais são a baliza de atuação Estatal e, para que sejam garantidos, legitima-se ampla atuação do Poder Judiciário, uma vez que esses direitos possuem estreita relação com o princípio da dignidade da pessoa humana. Sobre a primazia dos direitos fundamentais sociais, destaca-se:

Daí que a primazia dos direitos fundamentais na ordem jurídica brasileira autoriza o controle da administração e de políticas públicas pelo Poder Judiciário. E essa possibilidade não se restringe aos direitos individuais, mas compreende também os direitos sociais (CINTRA, 2016, p. 100).

Assim, os titulares dos direitos fundamentais, sempre que não tiverem garantidos esses direitos, podem recorrer às vias judiciais como forma de forçar o Estado ao cumprimento dessa importante obrigação que lhe foi imposta pelo constituinte.

Porém, numa análise superficial, a delimitação de competências entre o juiz e o legislador não oferece muitas controvérsias, mas em um Estado Constitucional, democrático e social de direitos e diante da força imanente dos direitos fundamentais, que vincula todos os setores da vida social e política, percebe-se, na prática, um espaço de aparente tensão, razão pela qual muitos doutrinadores criticam a judicialização sob o argumento de que o juiz, ao interferir nas políticas públicas, acaba extrapolando sua área de atuação. 
Nesse sentido, assevera Melo (2010, p. 346-347): "hoje em dia ninguém mais discute se o juiz dispõe ou não de poder criativo no exercício de sua função decisória; o que se discute atualmente é a amplitude desse poder criativo do juiz moderno".

No Brasil o juiz tem o dever de analisar a compatibilidade de normas infraconstitucionais com a Carla Magna e a sua atuação para garantia de direitos fundamentais sociais é imperativo previsto pelo constituinte. Logo, uma vez provocado, o judiciário não tem a opção de se pronunciar ou não sobre questões relevantes. Contudo, a forma como os juízes exercem a competência que lhes é devida é determinante para a existência ou não de ativismo judicial.

Desse modo, segundo destaca Barroso (2013, p. 232), ativismo judicial é uma expressão "cunhada nos Estados Unidos e que foi empregada, sobretudo, como rótulo para qualificar a atuação da Suprema Corte durante os anos em que foi presidida por Earl Warren entre 1954 e 1969". Porém, o mesmo autor destaca que a expressão, da forma que foi introduzida na prática, nos Estados Unidos, assumiu uma "conotação negativa, depreciativa, equiparada ao exercício impróprio do poder judicial” (BARROSO, 2013, p. 233).

Isso porque ativismo judicial se relaciona à ideia de uma ampla e indiscriminada participação do Poder Judiciário na concretização dos objetivos constitucionais, atuação, porém, que se dá com interferência na área de atuação dos outros poderes, ainda que não haja o confronto em si, mas a mera atuação na ausência de atitude dos demais poderes.

Contudo, é preciso que haja diferenciação entre o ativismo e a judicialização e, sobre isso, esclarece Barroso (2013, p. 234):

\begin{abstract}
A judicialização como demonstrado acima, é um fato, uma circunstância do desenho institucional brasileiro. Já o ativismo é uma atitude, a escolha de um modo específico e proativo de interpretar a Constituição, expandindo o seu sentido e alcance. (...). O oposto do ativismo é a auto-contenção judicial, conduta pela qual o judiciário procura reduzir sua interferência nas ações dos outros Poderes.
\end{abstract}

Nesse contexto, a principal diferença se perfaz no fato de que no ativismo o julgador procura extrair o máximo do texto constitucional, dando-lhe eficácia prática, mesmo que para isso precise interpretar enunciados vagos ou principiológicos.

A maior crítica ao ativismo como postura do judiciário é a mesma já tratada acima, o fato de que os juízes e membros judiciais não são agentes políticos eleitos. Ademais, alguns 
autores sustentam que a transferências do debate que deveria ser essencialmente político para os tribunais expõe o judiciário, o que pode acabar por comprometer sua imparcialidade.

Porém, é fato que o direito é diferente da política, mas nunca conseguirá ser isolado dela. Ademais, a atuação do Judiciário é intensificada pela omissão dos demais poderes, mas isso não quer dizer, necessariamente, rompimento da separação entre os Poderes, tampouco que o Judiciário está atuando de forma indevida, ou seja, quer dizer apenas que, consideradas as demandas sociais, o Judiciário tem assumido nova postura, mas sempre baseada nos valores e determinações do constituinte.

Nesse sentido, assevera Dias (2013, p.19):

Desse modo a segregação das funções estatais é um compromisso com a tutela de direitos fundamentais. O fato de que o Poder Judiciário está sendo demandando para concorrer com a atuação dos demais poderes ou funções não significa que o primado da separação esteja sendo enfraquecido ou colocado em risco.

As pretensões das sociedades massificadas contemporâneas têm exigido não a superação da separação entre as funções estatais, mas sim uma nova dinâmica institucional (...).

E, mais ainda, a atuação do juiz contemporâneo, constitucional por excelência, não pode se dar somente baseada no formalismo procedimental, pois, na realidade, nenhuma decisão se distanciará totalmente da política, uma vez que o conflito posto para decisão dos magistrados quase sempre envolve uma ordem valorativa, para que haja uma perfeita conformação entre a realidade social e o ideal de garantia de direitos fundamentais previsto na constituição. Por isso, pode-se afirmar que:

\begin{abstract}
A fundamentação material pela argumentação em cada caso concreto, dados os valores constitucionais que campeiam todo o agir estatal, não coloca a jurisdição como atividade que solucionará todos os problemas sociais, pois essa não é a sua função primordial, nem mesmo secundária; contudo, para a proteção dos direitos escolhidos pelo Poder Constituinte faz-se necessário uma posição mais ativa, ou melhor dizendo, mais aguçada no sentido de vigiar os outros Poderes no que tange a averiguar se os mesmos estão ou não cumprindo as suas funções constitucionais (SAMPAIO JÚNIOR, 2010, p. 421).
\end{abstract}

Desse modo, é evidente que cabe aos Poderes Executivo e Legislativo por excelência a realização de políticas públicas garantidoras de direitos fundamentais sociais, dentro do que estabelece a clássica separação de poderes. Mas, a jurisdição, se provocada, não deve se esquivar de atuar para promover, materialmente, a garantia desses direitos. 
Assim, a atuação ampliada do Poder Judiciário no Brasil deve ser compreendida com naturalidade e como uma atuação regular, própria da missão que lhe pertence de assegurar a efetividade dos valores constitucionais, especialmente em face do princípio da dignidade da pessoa humana. Esta atuação, mesmo que classificada como ativismo, tem seu único limite no próprio texto constitucional, e este já estabelece ampla atuação quando o objeto de defesa são os direitos fundamentais sociais.

\section{CONSIDERAÇÕES FINAIS}

Nos termos do que foi explanado no presente artigo, conclui-se que o princípio da dignidade da pessoa humana é imposto pelo constituinte como baliza de toda atuação Estatal e impõe que os direitos fundamentais sociais sejam garantidos amplamente.

Nesse sentido, é a CRFB/88 paradigmática e as normas que instituem direitos fundamentais são dotadas de imperatividade, o que significa dizer que o Estado the deve fiel cumprimento, de modo a garantir aos indivíduos uma vida digna.

Desse modo, as normas constitucionais definidoras de direitos fundamentais sociais irradiam força normativa que vincula todos os poderes. Assim, quando o judiciário é provocado pelos legítimos titulares de direitos fundamentais não pode eximir-se de dar total efetividade ao mandamento do constituinte, isso porque a garantia desses direitos é imperativa do princípio de dignidade da pessoa humana e dos próprios objetivos do Estado Social e Democrático de Direito.

Isso, evidentemente, não implica uma inversão de funções entre os poderes, ou mesmo uma invasão do espaço alheio, uma vez que toda atuação do Poder Judiciário se dá nos limites legais e para garantia da vontade do legislador constituinte. Logo, a atividade jurisdicional eminentemente constitucional impõe ao Magistrado o controle das Políticas Públicas no caso específico, sempre para proteger direitos fundamentais, sem que isso se constitua uma atuação indevida na esfera dos demais poderes.

Assim, a democracia não pode ser compreendida simplesmente como a possiblidade de escolha dos governantes, ou seja, atividade meramente formal, mas deve ser vista muito além, como a possibilidade de materialização dos direitos destes cidadãos que escolhem, de

Rev. de Direitos Fundamentais nas Relações do Trabalho, Sociais e Empresariais | e-ISSN: 2525-9903 | Maranhão | v. 3 | n. 2 | p. 44 - 65 | Jul/Dez. 2017 
modo que diante de uma omissão ou lesão aos seus direitos possam reclamar por eles, sendo a tutela jurisdicional a mais ampla expressão de justiça social.

Desse modo, essa nova forma de atuação jurisdicional deve ser compatibilizada com o princípio democrático, justamente para que não haja intromissão nas atribuições dos demais poderes, pois isso não é o objetivo desta forma de concepção da atuação jurisdicional. $\mathrm{Na}$ verdade, a atuação do judiciário é imprescindível para que a própria democracia se materialize e a baliza de atuação é a própria constituição.

Por fim, democracia só existe quando os direitos dos cidadãos são garantidos. Assim, privar o cidadão de seus direitos fundamentais sociais garantidos constitucionalmente é negarlhe dignidade, o que, em última análise lhe furta a própria condição de ser humano, pois a dignidade só pode ser valor supremo se os direitos fundamentais forem garantidos a todos na integralidade, e diante da omissão dos Poderes Legislativo e Executivo deve o Judiciário atuar, tudo para que os direitos e garantias fundamentais sejam respeitados por todas as Autoridades Públicas.

\section{REFERÊNCIAS}

ALCALÁ, Humberto Nogueira. Los derechos económicos, sociales y culturales como derechos fundamentales efectivos em el constitucionalismo democrático latino-americano. Estudios Constitucionales, Santiago, v. 7, n. 2, p. 143-205, 2009. Disponível em: <http://www.scielo.cl/scielo.php?script=sci_arttext\&pid=S0718-52002009000200007>. Acesso em: 03 jan. 2017.

BARCELLOS. Ana Paula de. A eficácia jurídica dos princípios constitucionais: O princípio da dignidade da pessoa humana. 3.ed.rev.atual. Rio de Janeiro: Renovar, 2011.

BARROSO, Luís Roberto. Constituição, democracia e supremacia judicial: direito e política no Brasil contemporâneo. In: As novas faces do ativismo judicial. Marcelo Nevelino et ali (Coords). Salvador: Jurispodivm, $2^{\text {a }}$ tiragem, 2013.

BUCCI, Maria Paula Dallari. O conceito de política pública em direito. In: BUCCI, Maria Paula Dallari (Org.). Políticas públicas - reflexões sobre o conceito jurídico. São Paulo: Saraiva, 2006.

BRASIL. Constituição da República Federativa do Brasil de 1988. Disponível em: <http://www.planalto.gov.br/ccivil_03/constituicao/constituicao.htm>. Acesso em: 12 abr. 2016.

BRITO FILHO, José Claudio Monteiro de. Direitos Humanos. São Paulo: LTr, 2015. 
CASTRO, Flavia de Almeida Viveiros de; VALLE, Caroline; ANSCHAU, Lorena Coser Doano; FERREIRA, Marcela Bravo. Análise do impacto das decisões judiciais sobre o orçamento da União no caso da saúde pública: Possibilidade e contingenciamento dos riscos. Revista Tributária e de Finanças Públicas, ano 20, volume 102, p. 15-40, 2012.

CINTRA, Fernando Vogel. Fundamentos do controle jurisdicional de políticas públicas no direito brasileiro: uma perspectiva comparada a partir do direito alemão. Revista da Defensoria Pública do Rio Grande do Sul. Porto Alegre, ano. 7, v. 14, jan. 2016. Disponível em: $<$ hhttps://issuu.com/defensoriapublicadoriograndedosul/docs/revista_da_defensoria_p_blica _ed_1>. Acesso em: 15 jan. 2017.

CUNHA JÚNIOR. A separação das funções estatais ante uma nova dogmática constitucional. In: TAVARES, André Ramos; LEITE, George Salomão; SARLET, Ingo Wolfgand (Coords.). Estado constitucional e organização do poder. São Paulo: Saraiva, 2010.

DUARTE, Clarisse Seixas. O ciclo das políticas públicas. In: SMANIO, Gianpaolo Poggio. BERTOLIN, Patrícia Tuma Martins. O Direito e as Políticas Públicas no Brasil. São Paulo: Atlas, 2013, p. 16-43 (capítulo 2).

DIAS, Jean Carlos. O controle judicial de políticas públicas. São Paulo: Método, 2007.

O controle judicial: direitos fundamentais e a teoria do processo. Revista de Direito Constitucional e Internacional da RT n. 83/abr-jun, 2013.

DWORKIN, Ronald. Levando os direitos a sério. Trad. Nelson Boeira. 3 ed. São Paulo: WMF Martins Fontes. 2010.

WMF Martins Fontes. 2005.

Uma questão de princípio. Trad. Luís Carlos Borges. 2 ed. São Paulo:

FARIA, José Eduardo. As transformações do judiciário em face de suas responsabilidades sociais. In: FARIA, José Eduardo (Org.). Direitos humanos, direitos sociais e justiça. São Paulo: Malheiros, 2002.

FERRAZ JÚNIOR, Tercio Sampaio. O judiciário frente à divisão dos poderes. In: Anuário dos Cursos de Pós-Graduação em Direito da UFPE. Recife, n. 11, 2000. p. 345-359.

GRAU, Eros Roberto. O direito posto e o direito pressuposto. São Paulo: Malheiros, 2005. p.26.

GRINOVER, Ada Pellegrini. O controle de políticas públicas pelo Poder Judiciário. Repro.164-p. 09-28.

LEAL, Saul Torinho. A nova face da jurisdição constitucional brasileira. In: NOVELINO, Marcelo et al. (Coords.) As novas faces do ativismo judicial. Salvador: Juspodivm, $2^{\mathrm{a}}$ tiragem, 2013, pp. 431-458.

Rev. de Direitos Fundamentais nas Relações do Trabalho, Sociais e Empresariais | e-ISSN: 2525-9903 | Maranhão | v. 3 | n. 2 | p. 44 - 65 | Jul/Dez. 2017. 
MELO, Gustavo Procópio Bandeira de. O juiz e o legislador, aspectos estruturais da justificação de seus atos. In: TAVARES, André Ramos; LEITE, George Salomão; SARLET, Ingo Wolfgand (Coords.). Estado constitucional e organização do poder. São Paulo: Saraiva, 2010.

OLIVEIRA, Carlos Alberto Alvaro de. Os direitos fundamentais à efetividade e à segurança em perspectiva dinâmica. Repro 155 , pp. 11-26.

SARLET, Ingo Wolfgang. A titularidade simultaneamente individual e transindividual dos direitos sociais analisada à luz do exemplo do direito à proteção e promoção da saúde. In: NOBRE, Milton Augusto de Brito; SILVA, Ricardo Augusto Dias da (Coord.). O CNJ e os desafios da efetivação do direito à saúde. 2.ed., Belo Horizonte: Fórum, 2013. p. 145-172.

- A eficácia dos direitos fundamentais: uma teoria geral dos direitos fundamentais na perspectiva constitucional. 12. ed. rev. atual e amp. Porto Alegre: Livraria do Advogado, 2015.

Dignidade da pessoa humana e direitos fundamentais na Constituição Federal de 1988. 9.ed., ver. atual. Porto Alegre: Livraria do Advogado, 2012.

SAMPAIO JÚNIOR, José Herval. Peculiaridades da atividade jurisdicional contemporânea e o princípio da separação dos poderes. In: TAVARES, André Ramos; LEITE, George Salomão; SARLET, Ingo Wolfgand (Coords.). Estado constitucional e organização do poder. São Paulo: Saraiva, 2010.

SANSON, Alexandre. Os grupos de Pressão e a Consecução de Políticas Públicas. In: SMANIO, Gianpaolo Poggio. BERTOLIN, Patrícia Tuma Martins. O Direito e as Políticas Públicas no Brasil. São Paulo: Atlas, 2013, p. 118-138 (capítulo 7).

SMANIO, Gianpaolo Poggio. Legitimidade Jurídica das Políticas Públicas: A Efetivação da Cidadania. In: SMANIO, Gianpaolo Poggio. BERTOLIN, Patrícia Tuma Martins. O Direito e as Políticas Públicas no Brasil. São Paulo: Atlas, 2013, p. 3-15 (capítulo 1).

Cidadania e Políticas Públicas. In: SMANIO, Gianpaolo Poggio; BERTOLIN, Patrícia Tuma Martins; BRASIL, Patricia Cristina. O Direito na Fronteira das Políticas Públicas. São Paulo: Páginas \& Letras Editora e Gráfica, 2015, p. 15 . 